University of Nebraska - Lincoln

DigitalCommons@University of Nebraska - Lincoln

\title{
Derivation of a tasselled cap transformation based on Landsat 7 at-satellite reflectance
}

C. Huang

USGS EROS Data Center, cqhuang@umd.edu

Wylie L. Yang

USGS EROS Data Center

Collin Homer

U.S. Geological Survey, homer@usgs.gov

G. Zylstra

USGS EROS Data Center

Follow this and additional works at: https://digitalcommons.unl.edu/usgsstaffpub

Part of the Geology Commons, Oceanography and Atmospheric Sciences and Meteorology Commons, Other Earth Sciences Commons, and the Other Environmental Sciences Commons

Huang, C.; Yang, Wylie L.; Homer, Collin; and Zylstra, G., "Derivation of a tasselled cap transformation based on Landsat 7 at-satellite reflectance" (2002). USGS Staff -- Published Research. 621.

https://digitalcommons.unl.edu/usgsstaffpub/621

This Article is brought to you for free and open access by the US Geological Survey at DigitalCommons@University of Nebraska - Lincoln. It has been accepted for inclusion in USGS Staff -- Published Research by an authorized administrator of DigitalCommons@University of Nebraska - Lincoln. 


\title{
Derivation of a tasselled cap transformation based on Landsat 7 at-satellite reflectance
}

\author{
C. HUANG, B. WYLIE, L. YANG, C. HOMER and G. ZYLSTRA \\ Raytheon ITSS, USGS EROS Data Center, Sioux Falls, SD 57198, USA; \\ e-mail: huang@usgs.gov
}

(Received 12 March 2001; in final form 19 October 2001)

\begin{abstract}
A new tasselled cap transformation based on Landsat 7 at-satellite reflectance was developed. This transformation is most appropriate for regional applications where atmospheric correction is not feasible. The brightness, greenness and wetness of the derived transformation collectively explained over $97 \%$ of the spectral variance of the individual scenes used in this study.
\end{abstract}

\section{Introduction}

The tasselled cap transformation is a useful tool for compressing spectral data into a few bands associated with physical scene characteristics (Crist and Cicone 1984). Originally constructed for understanding important phenomena of crop development in spectral space (Kauth and Thomas 1976), the transformation has potential applications in revealing key forest attributes including species, age and structure (e.g. Cohen et al. 1995).

Essentially two tasselled cap transformations have been developed based on Landsat Thematic Mapper (TM)-one based on digital number (DN) (Crist and Cicone 1984) and the other on reflectance factor (Crist 1985), which for simplicity will be referred to as DN based and reflectance factor based transformations, respectively. While the similar spectral characteristics of TM and the Landsat 7 Enhanced Thematic Mapper Plus (ETM +) might suggest direct applicability of both transformations to ETM + images (Crist and Kauth 1986), an at-satellite reflectance based transformation is needed for large area applications for the following reasons. First, the reflectance factor based transformation was developed based on ground measurements with little atmospheric effects (Crist 1985). Applying this transformation to satellite images requires the images to be corrected for atmospheric effects. Although several atmospheric correction algorithms have been developed (e.g. Liang et al. 1997), for large area applications, many users are still concerned with possible unknown errors that may arise due to lack of (or uncertainties in the) ground and atmospheric data necessary for running these algorithms, and therefore, often choose not to perform atmospheric correction (e.g. Cohen et al. 2001). Second, use of the DN based transformation in multi-scene applications can be problematic, because changing sun illumination geometry greatly affects DN, and thus affects the derived tasselled cap value. As will be demonstrated in $\$ 3.1$, a large part of the impact of

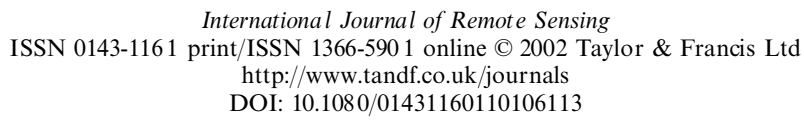


illumination geometry can be normalized by converting DN to at-satellite reflectance. Therefore, a transformation based on at-satellite reflectance is more appropriate for regional applications where atmospheric correction is not feasible.

The purpose of this Letter is to demonstrate the necessity to convert DN to at-satellite reflectance when atmospheric correction is not feasible, and to derive an at-satellite reflectance based tasselled cap transformation. Full explanation of the basic tasselled cap concept and its characteristics was provided in Kauth and Thomas (1976) and Crist and Cicone (1984).

\section{Data and methods}

A set of 5 pairs of clear and near cloud-free ETM + scenes representing both leaf-on and leaf-off conditions for a variety of landscapes of the United States were used in this study (table 1). These images were radiometrically and geometrically corrected in the EROS Data Center of the US Geological Survey using standard methods (Irish 2000). Raw digital number was converted to at-satellite reflectance according to Markham and Barker (1986) and the Landsat 7 Science Data Users Handbook (Irish 2000).

The impact of sun illumination geometry was demonstrated using pseudoinvariant objects including large flat building roofs, airport runways, large parking lots and deep water. These objects were identified visually from each of the five pairs of ETM + scenes.

The at-satellite reflectance based tasselled cap transformation was derived using the method described in Crist and Cicone (1984). About 2000 random samples were selected from each of the 10 ETM + scenes. A principal component analysis was performed on all random samples to define the initial principal axes. With the orthogonality of all six axes preserved, the transformation was derived through a

Table 1. Landsat 7 ETM + images used in this study.

\begin{tabular}{lcllc}
\hline Path & Row & $\begin{array}{c}\text { Geographic } \\
\text { location }\end{array}$ & $\begin{array}{c}\text { Acquisition } \\
\text { date (all in 1999) }\end{array}$ & $\begin{array}{c}\text { Variance } \\
\text { explained (\%)* }\end{array}$ \\
\hline 15 & 34 & Virginia, east & 28 July & 99.50 \\
15 & 34 & Virginia, east & 17 November & 99.12 \\
16 & 34 & Virginia, west & 19 July & 99.35 \\
16 & 34 & Virginia, west & 8 November & 98.82 \\
31 & 30 & Nebraska & 12 July & 98.37 \\
31 & 30 & Nebraska & 17 November & 97.96 \\
39 & 31 & Utah & 4 July & 99.31 \\
39 & 31 & Utah & 24 October & 99.42 \\
46 & 29 & Oregon & 22 August & 99.36 \\
46 & 29 & Oregon & 28 December & 99.19 \\
\hline
\end{tabular}

* Percentage of the variance of all six spectral bands explained by the first three axes of the at-satellite reflectance based tasselled cap transformation.

$\overline{\text { Figure 1. Pseudo-invariant objects selected from the Nebraska scene (path 31/row 30) have }}$ quite different DN values between summer and fall/winter. Many of the differences are removed by converting the DN to at-satellite reflectance. The units for both $\mathrm{x}$ - and $\mathrm{y}$-axis are $(a) \mathrm{DN}$ value and $(b)$ at-satellite reflectance $\times 400$. Each point represents a pseudo-invariant object. The plots for pseudo-invariant objects selected from the other four pairs of ETM + scenes are similar. 
Band 1

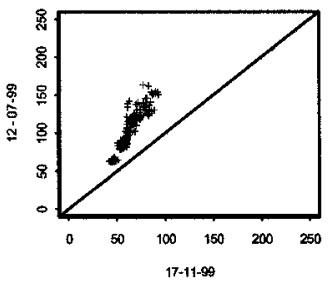

Band 2

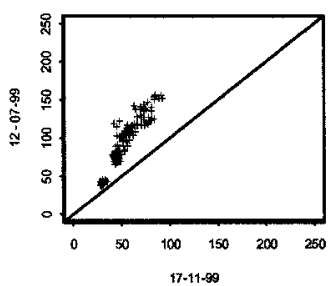

Band 3

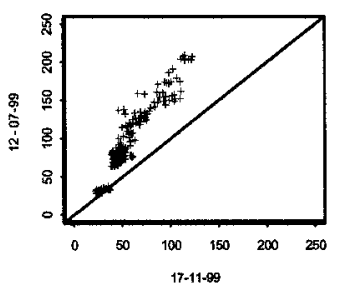

Band 4

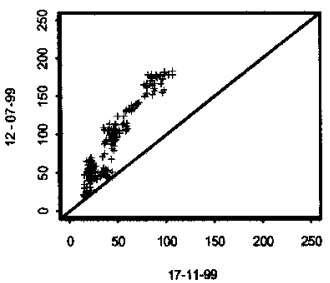

Band 5

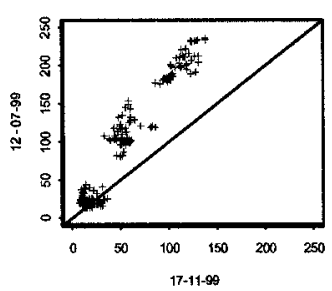

Band 7

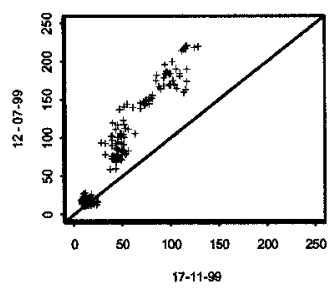

(a)

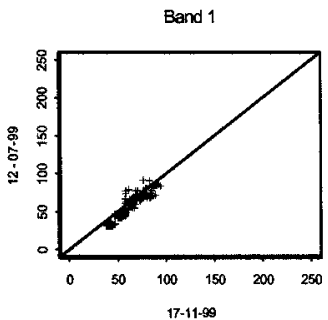

Band 2

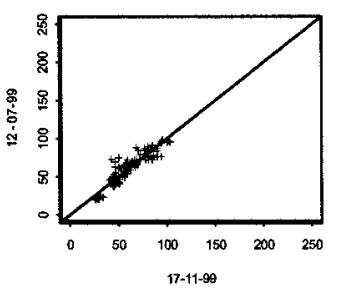

Band 3

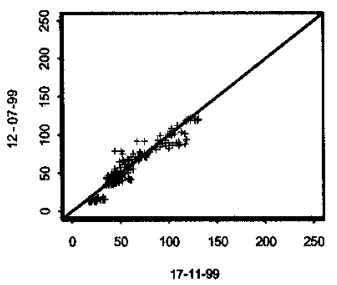

Band 4

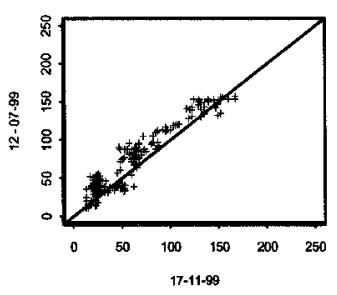

Band 5

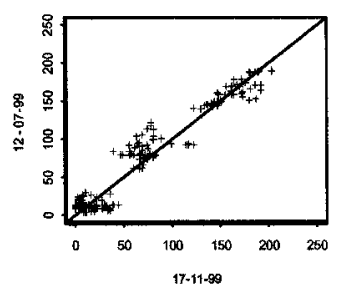

Band 7

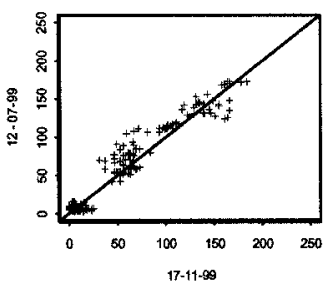

(b) 
Table 2. Tasselled cap coefficients for Landsat 7 ETM + at-satellite reflectance.

\begin{tabular}{lrrrrrr}
\hline Index & Band 1 & Band 2 & Band 3 & Band 4 & Band 5 & Band 7 \\
\hline Brightness & 0.3561 & 0.3972 & 0.3904 & 0.6966 & 0.2286 & 0.1596 \\
Greenness & -0.3344 & -0.3544 & -0.4556 & 0.6966 & -0.0242 & -0.2630 \\
Wetness & 0.2626 & 0.2141 & 0.0926 & 0.0656 & -0.7629 & -0.5388 \\
Fourth & 0.0805 & -0.0498 & 0.1950 & -0.1327 & 0.5752 & -0.7775 \\
Fifth & -0.7252 & -0.0202 & 0.6683 & 0.0631 & -0.1494 & -0.0274 \\
Sixth & 0.4000 & -0.8172 & 0.3832 & 0.0602 & -0.1095 & 0.0985 \\
\hline
\end{tabular}

sequence of rotations. Several hundreds of soil, impervious surface, dense vegetation and water samples were selected from the 10 scenes to guide the rotations.

\section{Results and discussion}

3.1. Impact of illumination geometry and its normalization

Figure 1(a) compares the DN values of the selected pseudo-invariant objects between summer and fall/winter. The values differed substantially between summer and fall/winter, though the reflective properties of those objects should be relatively stable over time. While the differences may be attributed to different atmospheric conditions or possible changes in the reflective property of the selected pseudoinvariant objects, the fact that most of them were removed by converting DN to at-satellite reflectance suggests that, for the five pairs of clear and near cloud-free images, the differences were mostly caused by changing illumination geometry (figure 1(b)). If the DN based transformation is applied to DN images, these pseudoinvariant objects likely will have different tasselled cap values between summer and fall/winter. Such impact of illumination geometry can confuse the analysis of real change signals that are characteristic of ground targets. Figure 1(b) suggests that for clear and cloud-free images, it is possible to remove much of this confusion by converting DN to at-satellite reflectance. The conversion method is physically based and easy to automate. Though it is also possible to normalize such impact by fitting a line between summer and fall/winter images using the pseudo-invariant objects (e.g. Schott et al. 1988), selecting pseudo-invariant objects can be time consuming and is often impractical for regional applications involving large numbers of scenes.

\subsection{The tasselled cap transformation}

Table 2 gives the coefficients for the derived tasselled cap transformation based on at-satellite reflectance. This transformation is not directly comparable to the DN based one because the two transformations are derived based on measurements of different physical units. The reflectance factor based transformation developed by Crist (1985), however, can be compared to the at-satellite reflectance based transformation because they are based on measurements of the same physical units. Generally, the three major axes-brightness, greenness and wetness, are defined by similar concepts for the two transformations, though the coefficients are not exactly the same. The relative locations of the soil, impervious surface, dense vegetation and water samples selected from the $10 \mathrm{ETM}+$ scenes in the two transformed spaces are also similar (figure 2). However, there is a major problem with applying directly the reflectance factor based transformation to at-satellite reflectance images: the greenness value of soil increases as its brightness value increases, making it difficult to differentiate bright soil pixels from some dark green vegetation pixels using the 

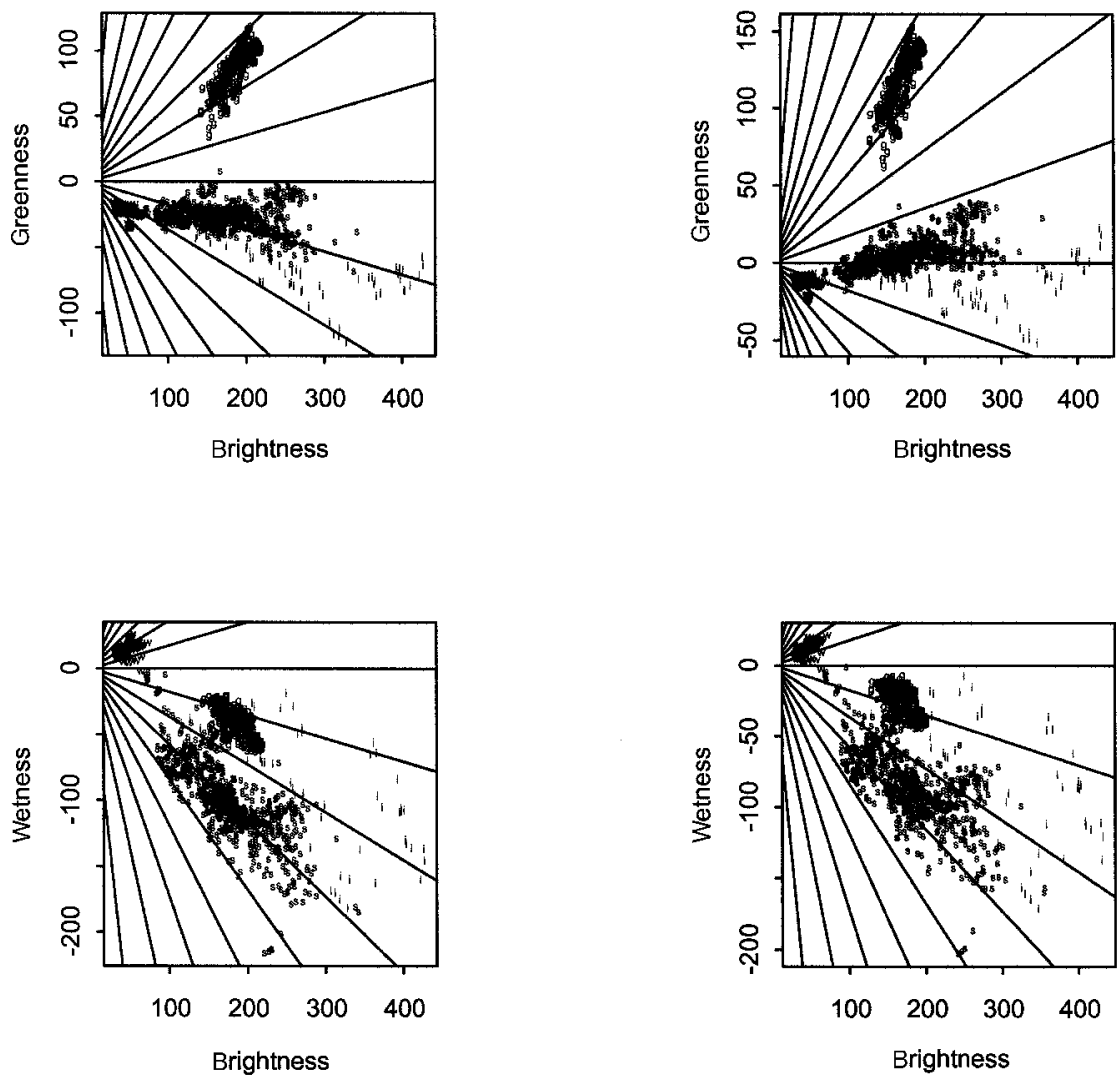

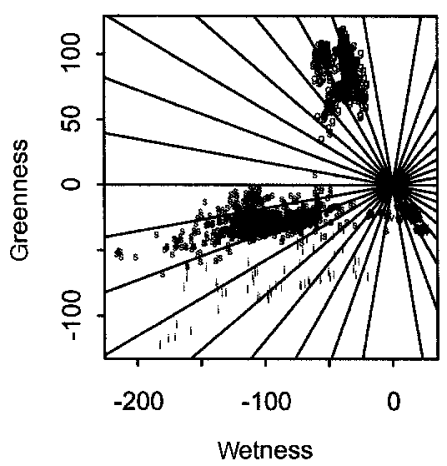

(a)

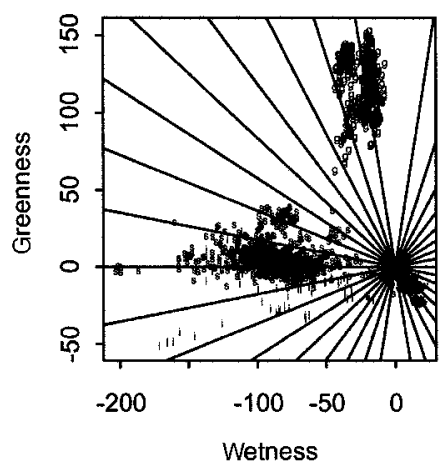

(b)

Figure 2. Soil ('s'), impervious surface ('i'), dense vegetation ('g') and water ('w') in the spaces of $(a)$ at-satellite reflectance based and $(b)$ reflectance factor based transformations. Both transformations were applied to at-satellite reflectance images rescaled by 400 (see figure 1(b)). The radial lines have a slope interval of 10 degrees and are used for visual aids. 


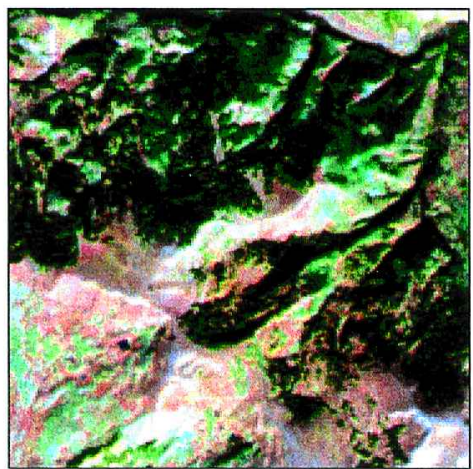

(a) ETM+ bands 5, 4 and 3 displayed as red, green and blue

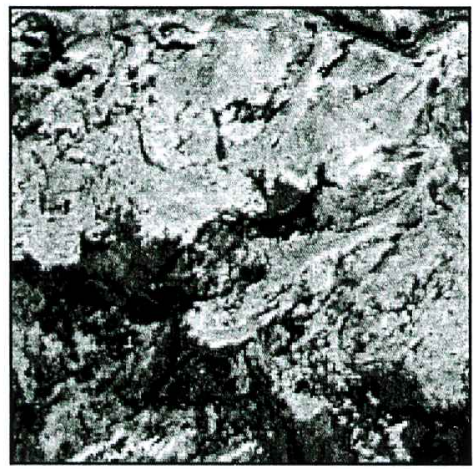

(c) At-satellite reflectance based greenness

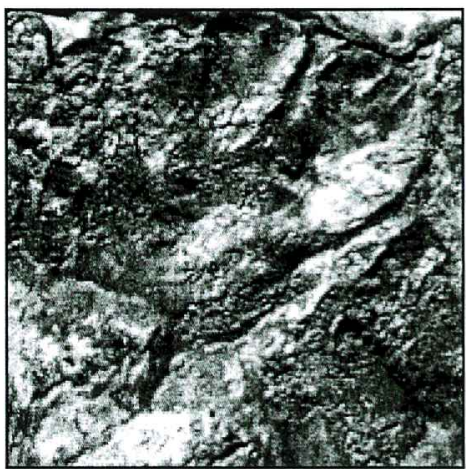

(b) Reflectance factor based greenness

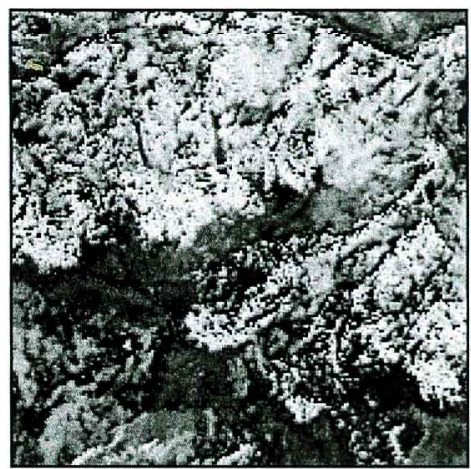

(d) NDVI

Figure 3. Greenness calculated by applying directly the reflectance factor based transformation to an at-satellite reflectance image might not be able to differentiate dark green vegetation from bright soil. The at-satellite reflectance based greenness image, however, is similar to the NDVI image, and they both reveal the spatial pattern of green vegetation. The $5.4 \mathrm{~km} \times 5.4 \mathrm{~km}$ image window was selected from an ETM + scene (path 38/row 32, acquired on 17 October 1999) not used in deriving the at-satellite reflectance based transformation.

greenness alone (figure 3 ). This problem is probably due to a stronger brightening effect of the atmosphere in the visible bands on dark soil than on bright soil (Kaufman 1989), which reduces the greenness value of dark soil more severely than does bright soil. The at-satellite reflectance based transformation does not have this problem when applied to at-satellite reflectance images. Figure 2 suggests that the at-satellite reflectance based transformation can differentiate water from land targets in the brightness-wetness space slightly better than the reflectance factor based transformation.

Many applications often use the first three components of the tasselled cap transformation and are concerned with the information content of the three components. The last column of table 1 shows that very high percentages of the spectral variance of individual images were explained by the first three components of the 
developed transformation. Considering the variety of landscapes represented by the 10 scenes, this at-satellite reflectance based transformation is probably applicable to clear and near cloud-free images for both leaf on and leaf off seasons over the conterminous United States.

\section{Conclusions}

An at-satellite reflectance based tasselled cap transformation was developed based on 10 Landsat 7 ETM + scenes representing a variety of landscapes of the United States in both leaf-on and leaf-off seasons. This transformation is most appropriate for regional remote sensing applications where atmospheric correction is not feasible. The DN based transformation is often not appropriate for this type of application, because DN value is strongly affected by changing illumination geometry. A large part of the impact of illumination geometry can be normalized by converting DN to at-satellite reflectance. Applying the ground reflectance factor based transformation directly to at-satellite reflectance images is not appropriate because it may result in unreasonable tasselled cap values. The at-satellite reflectance based transformation generally does not have this problem when applied to clear and near cloud-free at-satellite reflectance images. The brightness, greenness and wetness of the derived transformation collectively explained over $97 \%$ of the spectral variance of individual scenes used in this study.

\section{Acknowledgment}

This study was made possible in part by the Raytheon Corporation under US Geological Survey contract 1434-CR-97-CN-40274.

\section{References}

Cohen, W. B., Majersperger, T. K., Spies, T. A., and Oetter, D. R., 2001, Modelling forest cover attributes as continuous variables in a regional context with Thematic Mapper data. International Journal of Remote Sensing, 22, 2279-2310.

Cohen, W. B., Spies, T. A., and Fiorella, M., 1995, Estimating the age and structure of forests in a multi-ownership landscape of western Oregon, USA. International Journal of Remote Sensing, 16, 721-746.

CRIST, E. P., 1985, A TM tasseled cap equivalent transformation for reflectance factor data. Remote Sensing of Environment, 17, 301-306.

CRIST, E. P., and Cicone, R. C., 1984, A physically-based transformation of Thematic Mapper data-the TM Tasseled Cap. IEEE Transactions on Geosciences and Remote Sensing, 22, 256-263.

Crist, E. P., and Kauth, R. J., 1986, The tasseled cap de-mystified. Photogrammetric Engineering \& Remote Sensing, 52, 81-86.

IRISH, R. R., 2000, Landsat 7 science data user's handbook, Report 430-15-01-003-0, National Aeronautics and Space Administration. http://ltpwww.gsfc.nasa.gov/IAS/handbook/handbook_toc.html.

Kaufman, Y. J., 1989, The atmospheric effect on remote sensing and its corrections. In Theory and applications of optical remote sensing, edited by G. Asrar (New York: John Wiley \& Sons).

Kauth, R. J., and Thomas, G. S., 1976, The tasseled cap-a graphic description of the spectral-temporal development of agricultural crops as seen in Landsat. In Proceedings of the Symposium on Machine Processing of Remotely Sensed Data, West Lafayette, Indiana, 29 June-1 July 1976 (West Lafayette, Indiana: LARS, Purdue University), pp. 41-51.

Liang, S., Vallah-Adl, H., Kalluri, S., Jaja, J., Kaufman, Y. J., and Townshend, J. R. G., 1997, An operational atmospheric correction algorithm for Landsat Thematic Mapper imagery over the land. Journal of Geophysical Research, 102, 17 173-17 186. 
MARKham, B. L., and BARKer, J. L., 1986, Landsat MSS and TM post-calibration dynamic ranges, exoatmospheric reflectances and at-satellite temperatures. EOSAT Landsat Technical Notes, 1, 3-8.

Schott, J. R., Salvaggio, C., and VolghoK, W. J., 1988, Radiometric scene normalization using pseudoinvariant features. Remote Sensing of Environment, 26, 1-16. 